\title{
Study on energy conservation and emission reduction of pure electric non-road mining dump truck
}

\author{
Huawei Zhang ${ }^{1}$, Yong $\mathrm{Ma}^{2}$, Zhenzhong Yang ${ }^{1,}{ }^{*}$, Lijun Wang ${ }^{1}$, Shuman $\mathrm{Guo}^{1}$, and Bin $\mathrm{Hao}^{3}$ \\ ${ }^{1}$ North China University of Water Resources and Electric Power, China \\ ${ }^{2}$ Zhengzhou Zhengyu Heavy Industries Co., Ltd., China \\ ${ }^{3}$ Zhengzhou Yutong Bus Co., Ltd., China
}

Keywords: open-pit mine area, non-road, pure electric mining dump truck.

\begin{abstract}
Non-road mobile machinery emits a large amount of pollutants, which has attracted wide attention. As one of the effective means of air pollution control, the application of new energy technology in the field of non-road mobile machinery is slightly inadequate. Mine dump trucks play an important role in the transportation of open-pit mining areas, but they have high power, high level of activity, and difficult to control pollutant emissions. In this study, field experiments were carried out in several open pit mines in China. By comparing with similar diesel engine powered vehicles, the potential of energy consumption and emission reduction was evaluated. Research shows that pure electric mine dump truck can effectively reduce energy consumption and emissions.
\end{abstract}

\section{Introduction}

In recent years, China's air pollution emission control has achieved remarkable results, and indicators such as the amount of major pollutant emissions and the number of days with good quality have been continuously improved[1]. In order to accelerate the improvement of environmental quality and win the battle to defend the blue sky, the State Council requires "overall planning, systematic planning, and precise policy implementation." For non-road mobile machinery, it is required to "strengthen the prevention and control of pollution from non-road mobile machinery, and promote the use of new and clean energy vehicles and ships [2]."

Non-road mobile machinery is an important part of mobile sources and an important source of air pollutants. In 2017, my country had 7.2 million construction machinery, combined with non-road mobile machinery such as agricultural machinery, ships, and airplanes, and its annual emissions of NOx and PM pollutants are equivalent to motor vehicle emissions[3]. Research on the mobile source emission inventory shows that pollutants emitted by non-road mobile sources have an adverse effect on air pollution in the Pearl River Delta, Beijing-Tianjin-Hebei and surrounding areas, and the Fenwei Plain. [4-6]

\footnotetext{
*Corresponding author: yzzho@163.com
} 
As one of the main mining methods of mine resources, open-pit mining has been widely used in mines all over the world. Due to the resource status and mining technology, China's small and medium-sized open-pit mines are numerous and widely distributed. There are many types and quantities of equipment using high-power diesel engines as power, high energy consumption, and the actual implementation of pollutant emission standards is not optimistic. Vehicles are mobile and flexible, and are an important mode of transportation in open air operations. The main disadvantages are large fuel consumption and high transportation costs [7].

With the increasingly stringent emission regulations of non-road mobile machinery, new energy technology has also become a key route for non-road mobile machinery and equipment to improve environmental friendliness. Based on the actual application of pure electric off-road mining dump trucks, this study analyzed the energy consumption and application of different mine areas. In addition, this paper estimates the emissions of traditional diesel mining vehicles under the same conditions, in order to provide reference and reference for the application of new energy technologies in non-road mobile sources.

\section{Equipment and methods}

\subsection{Pure electric mining dump truck}

Non-road mining dump trucks (also known as non-road wide-body dump trucks) are special transportation equipment developed based on heavy dump trucks in recent years to meet the needs of China's open-pit mine area transportation links. Because its power and reliability are better than ordinary road heavy trucks, it is more suitable for non-road harsh working conditions, and is widely used in open-pit mines, hydropower projects, cement mines, stone mines and other earthwork and loose material transportation scenarios. The power transmission system of this kind of products mostly adopts diesel engine matching multi-stage reduction mechanism to achieve the purpose of deceleration and torque increase and improve power performance. The experimental equipment is the first pure electric product of its kind as shown in Figure 1.

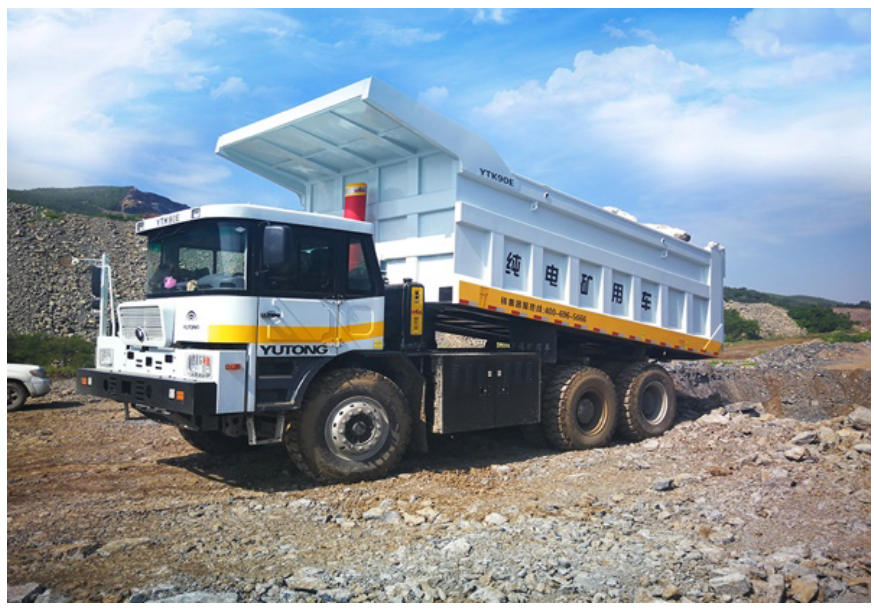

Fig. 1. Experimental Pure Electric Non-road Mining Dump Truck.

Some parameters of pure electric mining dump truck are shown in Table 1. 
Table 1. Some parameters of pure electric off-road mining dump truck.

\begin{tabular}{|l|l|}
\hline \multicolumn{1}{|c|}{ Product parameters } & \multicolumn{1}{c|}{ Parameters to describe } \\
\hline Model & YTK90 \\
\hline Equipment weight $(\mathrm{kg})$ & 30000 \\
\hline Maximum rated load $(\mathrm{kg})$ & 60000 \\
\hline Total mass of design & 90000 \\
\hline Length*width*height $(\mathrm{mm})$ & $9175 * 3400 * 3930$ \\
\hline Front and rear track $(\mathrm{mm})$ & $2710 / 2500$ \\
\hline Wheelbase $(\mathrm{mm})$ & $3800+1550$ \\
\hline
\end{tabular}

\subsection{Open-pit mine area transportation conditions}

Open-pit mine area transportation efficiency and energy consumption are closely related to factors such as the geographical environment, mining technology, and operation behavior of the mine area. Automobile transportation can be used as a separate transportation method in the open-pit mine, or it can be used in conjunction with other transportation methods. The high flexibility and maneuverability make the automobile transportation method widely used. However, automobile transportation is greatly affected by the climate and easily causes air pollution in and around the stope.

During open-pit mine area operations, the material loading and unloading points are often not fixed, and the transportation route will often change. The mine area has a short transportation distance, usually no more than $10 \mathrm{~km}$ one way. The road gradient varies greatly, the road surface is complicated, and the average speed is low. For the convenience of analysis, the research divides the vehicle transportation operating conditions into uphill (heavy or no-load) driving, straight road driving (heavy or no-load), and downhill (heavy or no-load) driving conditions as shown in the Figure 2.

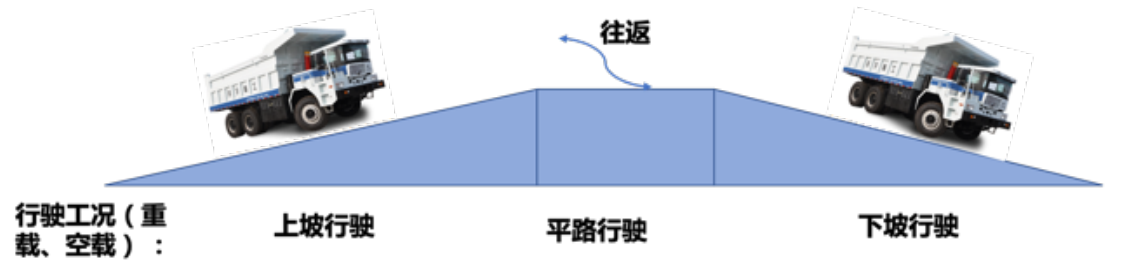

Figure 2. Open-pit Mine Area Transportation Conditions

During operation, transport vehicles travel between the loading area and the unloading area, and both uphill and downhill conditions under heavy load and no-load conditions will appear.

As far as diesel-powered mining vehicles are concerned, due to the large load capacity, the difference between full load and no load has a great influence on fuel consumption. The heavy-load climbing stage is the stage where vehicle fuel consumption increases the fastest, and the no-load downhill stage is the lowest fuel consumption stage. During the entire transportation cycle, the vehicle is braked frequently during the no-load return trip and downhill driving conditions, but the vehicle braking energy is not effectively used. In new energy road vehicles, braking energy recovery technology has been widely used and has achieved very good results. It can be imaged that the braking energy recovery technology has great potential for utilization in pure electric mining vehicles, and it is possible to reduce the energy consumption of the transportation link while improving the transportation capacity. 


\subsection{Energy consumption analysis based on field survey}

In order to evaluate the energy consumption and emissions of pure electric non-road mining dump trucks and traditional diesel-powered non-road mining dump trucks, this study investigated 10 open-pit mine areas and recorded fuel consumption and electric energy under the same working conditions. Part of the information of the field survey is shown in Table 2.

During the test, the selected mine area is distributed in Henan, Inner Mongolia, Xinjiang, Tibet, Guangdong, Yunnan, Jiangsu and other places, basically covering the typical open-pit mine area and part of the port operation area in the east, south, west, north and central China. The mine area is numbered $\mathrm{Ai}$, ( $\mathrm{i}=1-10$, representing 10 different mine areas). As the slope of the mine area pavement varies greatly, take the average slope value.

Table 2. Different mine area conditions.

\begin{tabular}{|l|l|l|l|}
\hline Test mine area & $\begin{array}{l}\text { One-way distance } \\
(\mathrm{m})\end{array}$ & Average slope $\left({ }^{\circ}\right)$ & Test duration $(\mathrm{h})$ \\
\hline $\mathrm{A}_{1}$ & 550 & 7 & 210 \\
\hline $\mathrm{A}_{2}$ & 2051 & 6.2 & 171 \\
\hline $\mathrm{A}_{3}$ & 1460 & 8 & 172 \\
\hline $\mathrm{A}_{4}$ & 970 & 6.5 & 334 \\
\hline $\mathrm{A}_{5}$ & 2800 & 3 & 229 \\
\hline $\mathrm{A}_{6}$ & 7895 & 5 & 160 \\
\hline $\mathrm{A}_{7}$ & 1000 & 0 & 42 \\
\hline $\mathrm{A}_{8}$ & 2000 & 3 & 379 \\
\hline $\mathrm{A}_{9}$ & 1000 & 7 & 832 \\
\hline $\mathrm{A}_{10}$ & 2900 & 5 & 304 \\
\hline
\end{tabular}

During the test of a pure electric vehicle, the vehicle mileage and power consumption are recorded through the on-board terminal, and the data recorded on the spot is comprehensively compared. Diesel-powered mining trucks are recorded by the on-site staff for fueling volume and operating mileage. The results are summarized and compared and analyzed. The test time is flexibly arranged according to the on-site situation, and the continuous work on the same road section is not less than 160h (A7mine area is a straight road, with simple working conditions and short test time). The longest working time reaches $830 \mathrm{~h}$ (A9mine area). The average time of 10 mine area tests is $283 \mathrm{~h}$. The comparison of power consumption and fuel consumption per kilometer for the same section of each mine area is shown in Figure 3.

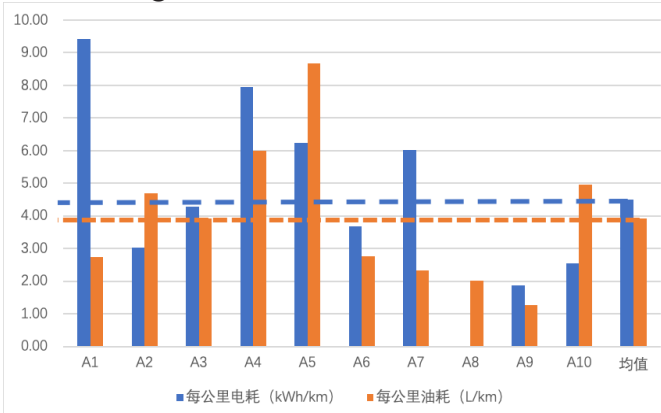

Fig. 3. Comparison of power consumption and fuel consumption per kilometer on the same road conditions in different mine areas.

It can be seen from table 2 and figure 3 that under the same working conditions, there is no obvious correlation between fuel consumption and energy consumption per kilometer, 
which means that there are many factors that affect vehicle energy consumption and the reasons are complicated.

The mine area road gradient has a great impact on the energy consumption of transportation vehicles [8]. Field surveys have calculated the proportions of heavy load uphill, heavy load downhill and peaceful road driving in the total operating mileage, as shown in Figure 4. Comparing Figure 3 and Figure 4, it can be found that the A8mine area is a heavy-duty downhill for the entire journey, and its power consumption per kilometer is 0 , and the corresponding diesel-powered mining vehicle has a lower fuel consumption per kilometer. Similarly, $\mathrm{A}_{3}, \mathrm{~A}_{6}, \mathrm{~A}_{9}, \mathrm{~A}_{10}$ mine area has a large proportion of heavy-load downhill sections, and the power consumption and fuel consumption per kilometer are lower than average, and the proportion of $\mathrm{A}_{2}$ heavy-load downhill conditions is not high. However, the proportion of flat road driving conditions is large, and the power consumption is also lower than average.

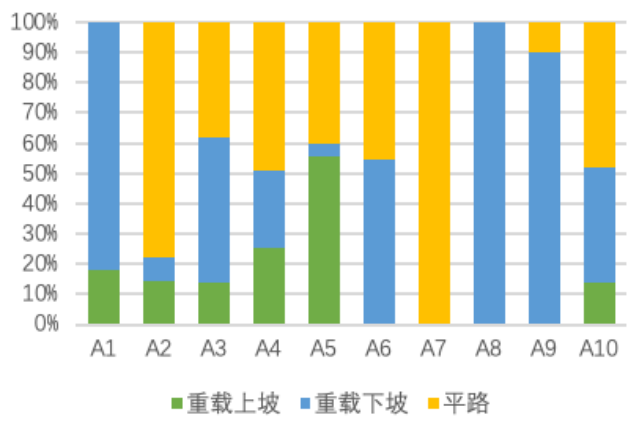

Fig. 4. Distribution of different mine area transportation conditions.

In order to facilitate the comparison of the energy consumption of the two vehicles, the electricity consumption and fuel consumption per kilometer are converted into standard coal quality for comparison. The calculation method is:

The coefficient of conversion of diesel to standard coal (c1) is $1.4571 \mathrm{~kg}$ of standard $\mathrm{coal} / \mathrm{kg}$ of diesel, and the coefficient of conversion of power consumption to standard coal (c2) is $0.123 \mathrm{~kg}$ of standard coal $/ \mathrm{kW} \cdot \mathrm{h}$ of electricity consumption. Table 3 shows the conversion of electricity consumption and fuel consumption per kilometer for different mine areas into standard coal.

Table 3. Comparison of fuel consumption and electricity consumption per kilometer in different mine areas converted to standard coal $(\mathrm{kg} / \mathrm{km})$.

\begin{tabular}{|c|c|c|c|}
\hline $\begin{array}{c}\text { mine area } \\
\text { code }\end{array}$ & Diesel/standard coal & Electricity/standard coal & $\begin{array}{c}\text { Energy saving } \\
\text { ratio }\end{array}$ \\
\hline $\mathrm{A}_{1}$ & 3.40 & 1.16 & $65.92 \%$ \\
\hline $\mathrm{A}_{2}$ & 5.81 & 0.37 & $93.56 \%$ \\
\hline $\mathrm{A}_{3}$ & 4.85 & 0.53 & $89.17 \%$ \\
\hline $\mathrm{A}_{4}$ & 7.42 & 0.98 & $86.84 \%$ \\
\hline $\mathrm{A}_{5}$ & 10.73 & 0.77 & $92.85 \%$ \\
\hline $\mathrm{A}_{6}$ & 3.42 & 0.45 & $86.80 \%$ \\
\hline $\mathrm{A}_{7}$ & 2.89 & 0.74 & $74.36 \%$ \\
\hline $\mathrm{A}_{8}$ & 2.50 & 0.00 & $100.00 \%$ \\
\hline $\mathrm{A}_{9}$ & 1.57 & 0.23 & $85.30 \%$ \\
\hline $\mathrm{A}_{10}$ & 6.14 & 0.31 & $94.91 \%$ \\
\hline
\end{tabular}

It can be found from table 3 that the use of pure electric transportation equipment can save a lot of energy under the same working conditions, with the lowest energy saving ratio of $65.92 \%\left(\mathrm{~A}_{1}\right)$ and the highest saving of $100 \%\left(\mathrm{~A}_{8}\right)$. In the $\mathrm{A}_{8}$ mine area, the whole process 
of heavy-load downhill, adopts braking energy recovery, and the recovered braking energy is not lower than the energy consumed by no-load uphill. Obviously, new energy technologies have great potential for energy saving in the open-pit mine area.

\subsection{Estimation of emission reduction ability of new energy technology}

This study estimates the potential of new energy technology applications to reduce pollutants emitted by transportation equipment in the open-pit mine area. For the convenience of comparison, the electricity consumption and fuel consumption are converted into the corresponding standard coal per kilometer, and the saved standard coal per kilometer is converted into the diesel consumption per kilometer. Refer to the "Technical Guidelines for the Compilation of Emission Inventories of Non-road Mobile Sources" [5] applicable to general methods of emission factors greater than 130kW, convert the energy consumption difference into diesel, and then estimate the PM, PM2.5, THC, NOx, CO emissions.

After pure electric technology is adopted, compared with diesel engine, under the same working condition:

Diesel fuel saved per kilometer $(\mathrm{kg})=$ fuel consumption per kilometer $(\mathrm{kg})$-power consumption per kilometer $(\mathrm{kW} \cdot \mathrm{h}) *$ (electricity consumption converted to standard coal factor/fuel consumption converted to standard coal factor). Based on this, calculate the amount of diesel fuel saved per kilometer for each mine area. Calculated as follows:

$$
\Delta F_{A i}=F_{A i}-\frac{C_{2}}{C_{1}} \times E_{A i}
$$

In the formula: $\triangle \mathrm{F}_{\mathrm{Ai}}$ : corresponds to the amount of diesel oil saved per kilometer $(\mathrm{kg})$ in the mine area $(\mathrm{Ai})$;

$\mathrm{c}_{1}$ : The coefficient of diesel conversion to standard coal is $1.4571 \mathrm{~kg}$ standard coal $/ \mathrm{kg}$ diesel;

$\mathrm{c}_{2}$ : The coefficient of power consumption converted into standard coal, $0.123 \mathrm{~kg}$ standard coal $/ \mathrm{kW} \cdot \mathrm{h}$ power consumption;

$\mathrm{E}_{\mathrm{Ai}}$ : the corresponding mine area $(\mathrm{Ai})$ power consumption per kilometer $(\mathrm{kW} \cdot \mathrm{h})$.

Table 4. Estimation of emission reduction potential of pure electric mining dump truck $(\mathrm{g} / \mathrm{km})$.

\begin{tabular}{|c|c|c|c|c|c|}
\hline $\begin{array}{c}\text { mine area } \\
\text { code }\end{array}$ & PM & PM2.5 & THC & NOx & CO \\
\hline $\mathrm{A}_{1}$ & 1.38 & 1.23 & 6.15 & 21.51 & 23.05 \\
\hline $\mathrm{A}_{2}$ & 3.36 & 2.98 & 14.92 & 52.21 & 55.94 \\
\hline $\mathrm{A}_{3}$ & 2.67 & 2.38 & 11.89 & 41.60 & 44.57 \\
\hline $\mathrm{A}_{4}$ & 3.98 & 3.54 & 17.70 & 61.93 & 66.36 \\
\hline $\mathrm{A}_{5}$ & 6.15 & 5.47 & 27.34 & 95.71 & 102.54 \\
\hline $\mathrm{A}_{6}$ & 1.84 & 1.63 & 8.16 & 28.55 & 30.59 \\
\hline $\mathrm{A}_{7}$ & 1.33 & 1.18 & 5.90 & 20.63 & 22.11 \\
\hline $\mathrm{A}_{8}$ & 1.54 & 1.37 & 6.86 & 24.03 & 25.74 \\
\hline $\mathrm{A}_{9}$ & 0.83 & 0.73 & 3.67 & 12.84 & 13.76 \\
\hline $\mathrm{A}_{10}$ & 3.60 & 3.20 & 16.00 & 55.98 & 59.98 \\
\hline
\end{tabular}

The diesel-powered transportation vehicles studied and compared are in compliance with China's Phase III standards for emission limits for non-road mobile machinery diesel engines. The emission factors for calculation [5] (g/kgFuel) are respectively 0.9 (PM), 0.8 (PM2.5), 4 (THC), 14 (NOx), 15 (CO), refer to the emission inventory calculation method $[9,10]$, calculate the emission reduction potential of pure electric mining dump truck relative to diesel per kilometer, the calculation formula is as follows: 


$$
E_{i, j}=\Delta F_{A i} \times E F_{j}
$$

In the formula, $E_{i, j}$ : corresponds to mine area (i), emissions of category $\mathrm{j}$ emissions $(\mathrm{g} / \mathrm{km})$;

$\mathrm{EF}_{\mathrm{j}}$ is the emission factors corresponding to pollutants.

The calculation results are shown in Table 4 .

It can be seen from Table 4 that after adopting pure electric mining vehicles, the diesel consumption per kilometer saved can potentially reduce the emissions of various pollutants. The data can provide support for further study of the Open-pit mine area non-road mobile machinery emission inventory and evaluation of the impact of new energy technologies on emissions.

\section{Conclusion}

1. New energy mining vehicles can adapt to the working environment of the Open-pit mine area. Under the same working conditions, the energy consumption converted into standard coal is much less than that of diesel-powered vehicles. It can save more than $65 \%$ of energy consumption per kilometer;

2. The reasons that affect the energy consumption of mining dump trucks are complex, but new energy mining vehicles can significantly reduce energy consumption in transportation links after using braking energy recovery. When the $A_{8}$ mine area is under full-load downhill conditions, the recovered braking energy can meet the requirements of no-load climbing;

3. The energy saved after adopting new energy mining vehicles is converted into diesel, and the potential for reducing PM, PM2.5, THC, NOx, CO and other pollutants is huge;

4. The open-pit mine area data provided in this study can provide technical support for the technology of non-road mobile machinery emission inventory and the application of new energy technologies.

Key scientific research projects of higher education institutions in Henan Province (20A470008); Key R\&D and promotion projects of Henan Province (182102311019); Funded by the Science and Technology Innovation Team Support Program of Universities in Henan Province (19IRTSTHN011)

\section{References}

1. Ministry of Ecological Environment of the People's Republic of China, http://www.mee.gov.cn/xxgk2018/xxgk/xxgk15/201806/t20180601_630217.html, 2018.

2. Ministry of Ecological Environment of the People's Republic of China, http://www.gov.cn/zhengce/content/2018-07/03/content_5303158.htm, 2018.

3. Ministry of Ecological Environment of the People's Republic of China, China Motor Vehicle Environmental Management Annual Report, 2018.

4. Zhang Lijun, Zheng Junyu, Yin Shasha, et al. Development of emission inventory for non-road mobile sources in the Pearl River Delta. Environmental Science, 2010, 31(4): $886 \sim 891$.

5. Ministry of Ecological Environment of the People's Republic of China, Technical Guidelines for Compilation of Non-road Mobile Source Air Pollutant Emission Inventory (Trial), 2015. 
6. Kui Xiao. The establishment of the Beijing-Tianjin-Hebei non-road mobile source emission inventory. In: Edited by the Chinese Society for Environmental Sciences. 2013 Annual Conference Proceedings of the Chinese Society for Environmental Sciences (Volume 3). Kunming, 2013. 1631 1637.

7. Zhou Wei. Research on self-driving whole-vehicle hoisting transportation system of open-pit mine trucks.: [Ph.D. Thesis], Northeastern University, 2006.

8. Soofastaei, Aminossadati, Kizil, Knights, A comprehensive investigation of loading variance influence on fuel consumption and gas emissions in mine haulage operation, International Journal of Mining Science and Technology, 2016(26).995 1001.

9. Fan Wang, Zhen Li, Kaishan Zhang. An overview of non-road equipment emissions in China, Atmospheric Environment,2016 (132).283-289.

10. Liu Fuming, Cai Qingxiang, Chen Shuzhao, Zhou Wei, A comparison of the energy consumption and carbon emissions for different modes of transportation in open-cut coal mines, International Journal of Mining Science and Technology, 2015 (25). 261-266 